\title{
Epidemiologic Characteristics of Renal Cell Carcinoma in Brazil
}

\author{
Aguinaldo C. Nardi, Stenio de C. Zequi, Otavio A. C. Clark, Jose C. Almeida, Sidney Glina
}

Brazilian Society of Urology

\begin{abstract}
Purpose: In Brazil, National data regarding the epidemiology of renal cell carcinoma (RCC) are scarce. The aim of this study was to describe the demographic, clinical, and pathologic characteristics of RCC diagnosed and treated by members of the SBU - Brazilian Society of Urology.

Materials and Methods: For this cross-sectional study, data were collected through an on line questionnaire available to the members of the Brazilian Society of Urology (SBU). Between May 2007 and May 2008, voluntary participant urologists collected data on demographic, clinical and pathological characteristics from patients diagnosed with RCC in their practice.

Results: Fifty SBU affiliated institutions contributed with patient information to the study. Of the 508 patients, $58.9 \%$ were male, $78.9 \%$ were white, and the mean age was 59.8 years. Smoking history, high blood pressure and a body mass index above $30 \mathrm{~kg} / \mathrm{m}^{2}$ were present in $14.8 \%, 46.1 \%$ and $17.9 \%$ of the patients, respectively. Abdominal ultrasound and computed tomography were the main diagnostic methods. The majority of the cases were localized tumors and metastasis were presented in $9.5 \%$ of the patients; $98.4 \%$ underwent nephrectomy. Clear cell carcinoma was the most common histological type. In comparison with private institutions, stage IV disease was less frequent among patients treated at public health services $(\mathrm{P}=0.033)$.

Conclusions: RCC in Brazil is more common in white men in their sixth decade of life. Ultrasound is the main diagnostic tool for the diagnosis of clear cell carcinoma and we found that localized disease was predominant. A national registry of $\mathrm{RCC}$ is feasible and may provide valuable information.
\end{abstract}

Key words: carcinoma; renal cell carcinoma; cross sectional studies; epidemiology; kidney neoplasms Int Braz J Urol. 2010; 36: 151-8

\section{INTRODUCTION}

The incidence of renal cell carcinoma (RCC) is increasing globally $(1,2)$. Currently, the disease represents approximately $2.0 \%$ of all new cases of cancer and over 100.000 deaths worldwide (3). Improvements in imaging diagnosis may have contributed to the rising incidence of $\mathrm{RCC}$ over the past three decades, since this rise in incidence is mainly a result of the increasing detection of small tumors (4). However, at least in the United States, both incidence of late-stage RCC and mortality rates due to the disease have also been rising, implying that improvements in the ability to diagnose RCC are being outweighed by the increasing prevalence of some of the risk factors for this tumor (5). 
In Brazil, data regarding the epidemiology of $\mathrm{RCC}$ on a national scale are currently scarce, since the disease is not among the 10 most frequent tumor types annually reported by the National Cancer Institute (6). Data from regional surveys suggest that RCC represents approximately $1.2 \%$ of all cases of cancer in the country (7). Recognizing the need for better information about the burden of RCC in Brazil, the Brazilian Urological Society (SBU) led the effort to produce this first-ever survey on a national scale describing the epidemiology of RCC in Brazil.

The aim of this study was to describe the demographic, clinical, and pathologic characteristics of $\mathrm{RCC}$ diagnosed and treated by urologists associated to SBU in Brazil.

\section{MATERIALS AND METHODS}

\section{Data Collection}

To perform a cross-sectional study, a webbased survey containing 75 questions was made available to approximately 3,700 physicians affiliated to SBU, who were invited to participate in the study through mailed announcements and frequent advertising of the study on the SBU website. The questionnaire was available on the website for the duration of the study, and could also be sent by regular mail or fax upon request (www.sbu.org.br). Participant physicians were instructed to collect data from patients seeking medical attention between May 2007 and May 2008. All completed questionnaires were registered in a central database that was under the supervision of SBU. The study was approved by the institutional review boards affiliated with the centers where participants were enrolled. An informed consent was offered for all patients and signed by them. The study was sponsored by Pfizer Brazil.

Data collected from each patient included age, gender, race, state of origin, weight, height, tumor-node-metastases (TNM) stage, histological subtype, the presence of known risk factor for RCC (history of smoking, hypertension, obesity, diabetes, hypercholesterolemia, end-stage renal disease, and Von Hippel-Lindau disease), signs and symptoms present at diagnosis (hematuria, palpable mass, flank pain, weight loss, fever, and night sweats), the exam leading to diagnosis (clinical findings, laboratory tests, or imaging studies), and type of medical assistance (public heath care, private care, or third-party payment by insurance companies; the latter two were combined for analysis under the category "private institutions").

Body-mass index (BMI), the weight in kilograms divided by the square of the height in meters, was calculated for each patient. TNM stage was determined according to the 2002 classification of renal tumors (8). Tumor histology was classified according to the Heidelberg classification (9). Five subtypes of RCC were reported in the study: clear-cell, papillary, chromophobe, collecting-duct, and unclassified carcinomas.

\section{Statistical Analysis}

In addition to descriptive statistics of the demographic, clinical, and pathologic variables, exploratory analyses were conducted for comparisons between groups of patients. The chi-square or Fisher's exact tests were used to compare the frequency of categorical variables between groups, and Student'st-test or analysis of variance were used to compare continuous variables. All $\mathrm{P}$ values are two sided, and $\mathrm{P}<0.05$ was considered significant. All data analysis was conducted using the MedCalc software, version 9.6.0.0 (MedCalc, Mariakerke, Belgium).

\section{RESULTS}

\section{Patient and Disease Profile}

Fifty SBU affiliated institutions from 14 Brazilian States contributed with patient data for this study. Each institution was represented by at least one physician and a total of 508 patients were enrolled. Approximately three-quarters of patients were seen at institutions from the State of São Paulo. Table-1 shows the distribution of patients according to State. Patient demographics and tumor characteristics are given in Table-2. Slightly more patients were male, nearly $80 \%$ were white and $83.5 \%$ were assisted by 
Table 1 - Distribution of patients according to Federation States.

\begin{tabular}{lcc}
\hline State of Enrollment & Number & Percent \\
\hline Bahia & 1 & 0.2 \\
Paraíba & 1 & 0.2 \\
Paraná & 2 & 0.4 \\
Goiás & 3 & 0.6 \\
Mato Grosso do Sul & 4 & 0.8 \\
Distrito Federal & 6 & 1.2 \\
Pará & 6 & 1.2 \\
Rio Grande do Sul & 8 & 1.6 \\
Sergipe & 9 & 1.8 \\
Piauí & 12 & 2.4 \\
Minas Gerais & 18 & 3.5 \\
Rio de Janeiro & 19 & 3.7 \\
Pernambuco & 24 & 4.7 \\
Espírito Santo & 26 & 5.1 \\
São Paulo & 369 & 2.6 \\
Total & 508 & 100.0 \\
\hline
\end{tabular}

public health services. The mean age was close to 60 years, and the most prevalent risk factor for RCC was hypertension. With regard to symptoms and signs upon presentation, hematuria (42.9\%) and flank pain
$(41.3 \%)$ were the most frequent, whereas the classic triad of hematuria, flank pain and palpable flank mass was present in only $4.5 \%$ of the cases (Figure-1). The most common procedure leading to the diagnosis of RCC was an abdominal ultrasound (73.4\%), followed by computed tomography (CT) scan of the abdomen (19.1\%) and physical exam (3\%). Diagnosis through intravenous urography was anecdotal $(0.6 \%)$. Threequarters of patients had localized disease (i.e., TNM stage I and II) and the most common histological type was clear cell carcinoma; virtually all patients underwent nephrectomy (radical or partial) for management of their RCC. Other patient and disease characteristics are shown in Table-2.

\section{Exploratory Analyses}

The presence of most risk factors for RCC varied little according to age. However, there were significantly higher proportion of patients with a history of hypertension $(\mathrm{P}<0.0001)$ or diabetes $(\mathrm{P}$ $=0.0011)$ among subjects aged 60 years or older, in comparison with younger patients. The proportion of cases diagnosed by ultrasound or by CT scan did not differ among patients seen at public health services or in private institutions $(\mathrm{P}=0.631)$. Metastatic disease

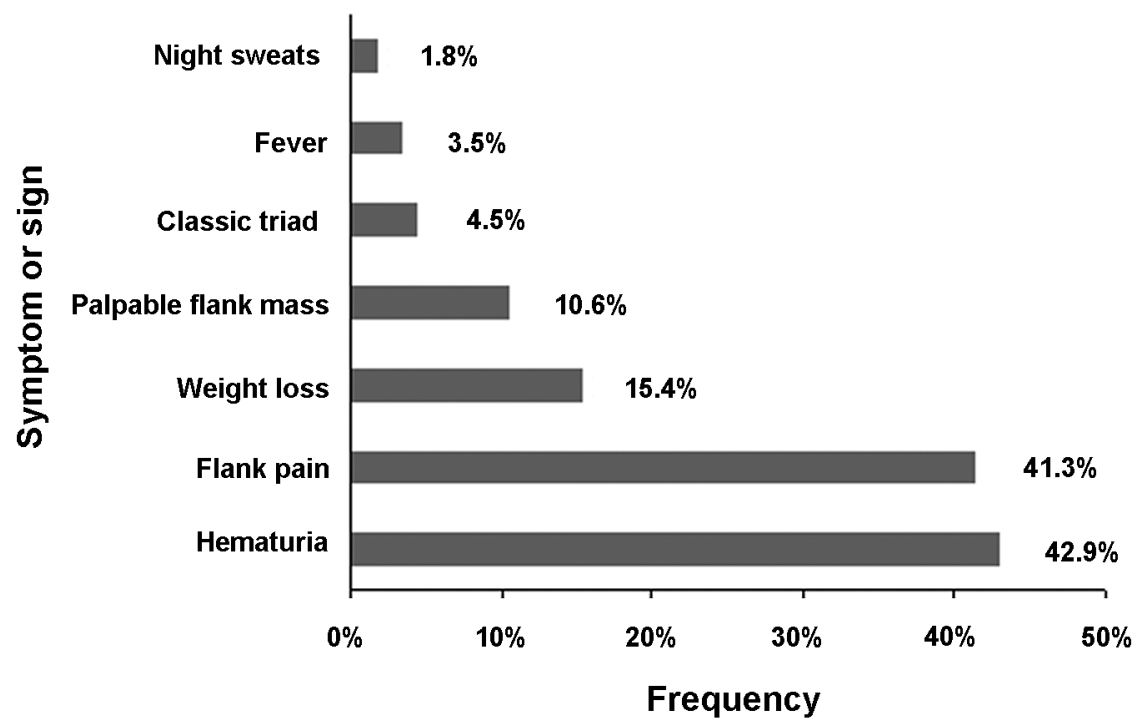

Figure 1 - Frequency of signs and symptoms at presentation of renal cell carcinoma. 
Table 2-Patient and tumor characteristics.

\begin{tabular}{|c|c|c|c|}
\hline Characteristic & & Number & Percent \\
\hline \multicolumn{4}{|l|}{ Age, years } \\
\hline Mean $( \pm \mathrm{SD})$, range & 59.8 ( \pm 12.3$), 24.6$ to 96.8 & & \\
\hline \multicolumn{4}{|l|}{ Sex } \\
\hline Female & & 209 & 41.1 \\
\hline \multicolumn{4}{|l|}{ Race } \\
\hline White & & 401 & 78.9 \\
\hline Black & & 33 & 6.5 \\
\hline Asian & & 3 & 0.6 \\
\hline Mixed race & & 71 & 14.0 \\
\hline \multicolumn{4}{|l|}{ Body mass index (BMI), $\mathrm{kg} / \mathrm{m}^{2}$} \\
\hline Mean $( \pm \mathrm{SD})$ & $26.8( \pm 5.2)$ & & \\
\hline History of smoking & & 75 & 14.8 \\
\hline Hypertension & & 234 & 46.1 \\
\hline $\mathrm{BMI}>30 \mathrm{~kg} / \mathrm{m}^{2}$ & & 91 & 17.9 \\
\hline End-stage renal disease & & 11 & 2.2 \\
\hline Von Hippel-Lindau disease & & 1 & 0.2 \\
\hline \multicolumn{4}{|l|}{ TNM stage } \\
\hline I & & 189 & 37.2 \\
\hline II & & 124 & 24.4 \\
\hline III & & 61 & 12 \\
\hline IV & & 48 & 9.5 \\
\hline Unknown & & 86 & 16.9 \\
\hline \multicolumn{4}{|l|}{ Histological subtype } \\
\hline Clear-cell carcinoma & & 374 & 73.6 \\
\hline Papillary carcinoma & & 33 & 6.5 \\
\hline Chromophobe carcinoma & & 46 & 9.1 \\
\hline Collecting-duct carcinoma & & 2 & 0.4 \\
\hline Unclassified & & 52 & 10.2 \\
\hline Unknown & & 1 & 0.2 \\
\hline Radical or partial nephrectomy & & 500 & 98.4 \\
\hline \multicolumn{4}{|l|}{ Type of medical assistance } \\
\hline Public health & & 424 & 83.5 \\
\hline Private & & 14 & 2.8 \\
\hline Insurance company & & 69 & 13.6 \\
\hline Unknown & & 1 & 0.2 \\
\hline
\end{tabular}

$S D=$ standard deviation. 
Table 3 - Exploratory analyses of TNM stage distribution according to clinical characteristics, presence of risk factors, histological subtype, and type of medical assistance.

\begin{tabular}{lccccc}
\hline & \multicolumn{2}{c}{ TNM Stage (\%) } & \multicolumn{2}{c}{ p Value } \\
Factors & I & II & III & IV & \\
\hline Age, mean (years) & 58.9 & 59.6 & 61.3 & 60.6 & 0.578 \\
Sex (\%) & & & & & \\
$\quad$ Female & 45.1 & 33.1 & 11.4 & 10.3 & 0.302 \\
$\quad$ Male & 44.5 & 26.7 & 16.6 & 12.1 & \\
History of smoking (\%) & 24.4 & 23.0 & 35.3 & 27.0 & 0.089 \\
Hypertension (\%) & 43.8 & 49.2 & 42.4 & 37.8 & 0.563 \\
BMI > 30 kg/m (\%) & 18.1 & 21.1 & 11.7 & 17.0 & 0.478 \\
End-stage renal disease (\%) & 2.1 & 1.7 & 1.7 & 0 & 0.799 \\
Histological subtype (\%) & & & & & \\
Clear-cell & 42.4 & 29.1 & 16.1 & 12.3 & 0.1626 \\
$\quad$ Others & 51.9 & 30.2 & 9.4 & 8.5 & \\
Medical assistance (\%) & & & & & \\
$\quad$ Public health & 83.6 & 92.7 & 83.6 & 22.9 & 0.033 \\
$\quad$ Private institution & 16.4 & 7.3 & 16.4 & 77.1 & \\
\hline
\end{tabular}

$B M I=$ body mass index.

was less frequent among patients seen at public health services $(\mathrm{P}=0.033)$, in comparison with those seen in private institutions. On the other hand, TNM stage was not associated with any of the other patient demographic characteristics, tumor histological subtype or risk factors (Table-3).

\section{COMMENTS}

This study provides a cross-sectional view of RCC in Brazil, a country where no national incidence rates for the disease are currently available $(6,7)$. In an attempt to overcome the paucity of data in our country, SBU carried out a nationwide study on the epidemiologic and clinical features of RCC in Brazil. As a result, a total of 508 patients were enrolled by physicians from 50 different institutions. Most demographic characteristics of the study cohort were quite similar to those in the existing literature (5), since male patients predominated, the majority was white, and the mean age was close to 60 years. Also, similar to what occurs in developed countries, most of the patients presented with localized disease $(37 \%$ with stage I RCC). The predominance of early-stage disease is corroborated by the fact that abdominal ultrasound $(73.4 \%)$ or abdominal CT scans (19.1\%) were main diagnostic methods in contrast to physical examination $(3.0 \%)$ and intravenous urography $(0.6 \%)$.

Tumor stage is considered one of the most important prognostic factors in RCC $(10,11)$. In our study, the proportion of patients with metastatic disease $(9.5 \%)$ was similar to that reported in other clinical series $(12,13)$. On the other hand, this proportion is lower than expected from population-based studies, in which patients with metastatic disease comprise between $25 \%$ and $30 \%$ of cases upon presentation (14). We did not find an association between TNM stage and patient or tumor-related characteristics. It is generally acknowledged that men present with more advanced disease at diagnosis. Aron et al., analyzing 35,336 cases of RCC from the Surveillance, Epidemiology, and End Results (SEER) registries database from 1973 to 2004, reported that male gender was associated with higher stage at presentation and 
poorer overall survival, compared with women (15). However, we did not find the same association in our sample. Similarly, there was no association between stage and the presence of risk factors for RCC in the present study. Smoking, hypertension and obesity are the most frequently recognized risk factors for RCC (16-18). Yet, the presence of risk factors did not seem to correlate with stage at presentation in the present series.

Several studies have evaluated the prognostic value of histological subtype in RCC. Although some studies have suggested that clear-cell histology is associated with a poorer survival (19), Patard et al. reported that in a multivariate analysis including TNM stage, Fuhrman nuclear grade and Eastern Cooperative Oncology Group performance status (PS), histological subtypes of RCC did not have an independent prognostic significance (12). Although we did not collect data on Fuhrman nuclear grade and PS, we did not find an association between the presence of clear-cell histology and more advanced disease. An obvious limitation of our study design is the lack of central pathologic review; therefore, we cannot exclude the possibility of histological subtype misclassification in some cases.

We found an association between TNM stage and type of medical assistance. Surprisingly, there was a higher proportion of early stage disease, especially stage II, among patients seen in public health care facilities, whereas patients seen at private institutions were more likely to present with metastatic disease $(\mathrm{P}=0.033)$. Such findings are in contrast to those obtained in another epidemiologic study conducted by SBU. In that cross-sectional survey of prostate cancer in the State of São Paulo, 30\% of the patients seen in public institutions were diagnosed with locally advanced or metastatic disease, compared with $21 \%$ of patients treated in the private sector $(20)$. The reasons for these findings are not clear, and we may only speculate as to possible explanations. One reason for the higher frequency of metastatic disease in the private sector could be referral bias, leading to more patients with advanced disease in the public institutions being referred to medical oncologists or palliative care. Another explanation could be the migration of patients diagnosed with metastatic disease to the private sector seeking for faster assistance. Alterna- tively, patients in the private sector could have undergone more extensive imaging assessment, leading to stage migration in this health care sector. The latter hypothesis, however, does not seem to be supported by our own finding of no significant difference in the proportion of cases diagnosed by ultrasound or by CT scan in the two sectors. Finally, the discrepancies in the proportions of patients with metastatic disease may have resulted from the play of chance or from the lack of data for complete classification of nearly $17 \%$ of patients.

The major drawback of the study was that participation of the urologists was on a volunteer basis and it did not include all the cases seen during the period. All SBU members were invited by mail to participate in this epidemiological survey. From the 76 institutions affiliated with the SBU, 50 (65.8\%) took part in this study. Although we had the participation of institutions from 14 Brazilian States, $72.6 \%$ of patients that were enrolled in the study were from one single State, São Paulo. Probably due the fact that São Paulo has the majority (31.6\%) of total SBU affiliated Institutions (24 of 76 institutions).

Although it could be filled out in a relative short period of time, the questionnaire used in this survey was rather long and required the review of medical charts, laboratory findings, imaging studies and pathology reports. Perhaps the use of shorter questionnaires aiming at more specific questions will be better accepted. Other strategies to increase participation of Brazilian urologists of the whole country in epidemiological surveys should be discussed.

Medical associations may provide many opportunities for productive research, especially for physicians not currently affiliated to academic institutions. Despite the limitations of the method, this study represents the largest collection of RCC cases in Brazil to date and shows that a registry is feasible and may provide valuable information regarding $\mathrm{RCC}$ in Brazil. We hope the present work will stimulate further participation of Brazilian urologists in future projects.

\section{CONFLICT OF INTEREST}

None declared. 


\section{REFERENCES}

1. Hollingsworth JM, Miller DC, Daignault S, Hollenbeck BK: Rising incidence of small renal masses: a need to reassess treatment effect. J Natl Cancer Inst. 2006; 98: 1331-4.

2. Mathew A, Devesa SS, Fraumeni JF Jr, Chow WH: Global increases in kidney cancer incidence, 19731992. Eur J Cancer Prev. 2002; 11: 171-8.

3. Parkin DM, Bray F, Ferlay J, Pisani P: Global cancer statistics, 2002. CA Cancer J Clin. 2005; 55: 74108.

4. Hollingsworth JM, Miller DC, Daignault S, Hollenbeck BK: Five-year survival after surgical treatment for kidney cancer: a population-based competing risk analysis. Cancer. 2007; 109: 1763-8.

5. McLaughlin JK, Lipworth L, Tarone RE: Epidemiologic aspects of renal cell carcinoma. Semin Oncol. 2006; 33: 527-33.

6. Brasil. Ministério da Saúde. Instituto Nacional do Câncer. Estimativa 2008: Incidência de Câncer no Brasil. Available at http://www.inca.gov.br/estimativa/2008 (Acessed 21/10/2008).

7. Mirra AP, Latorre MRDO, Veneziano DB. (ed.); Incidência de Câncer no Município de São Paulo, Brasil 1997-1998: mortalidade de Câncer no Município de São Paulo, Brasil: tendência no Período de 1969-1998. Brasília, DF: Ministério da Saúde, 2001.

8. Sobin LH, Wittekind C: TNM Classification of Malignant Tumours. 6th ed. Hoboken, New Jersey: John Wiley \& Sons. 2002.

9. Kovacs G, Akhtar M, Beckwith BJ, Bugert P, Cooper CS, Delahunt B, et al.: The Heidelberg classification of renal cell tumours. J Pathol. 1997; 183: 131-3.

10. Kattan MW, Reuter V, Motzer RJ, Katz J, Russo P: A postoperative prognostic nomogram for renal cell carcinoma. J Urol. 2001; 166: 63-7.

11. Zisman A, Pantuck AJ, Dorey F, Chao DH, Gitlitz BJ, Moldawer N, et al.: Mathematical model to predict in- dividual survival for patients with renal cell carcinoma. J Clin Oncol. 2002; 20: 1368-74.

12. Patard JJ, Leray E, Rioux-Leclercq N, Cindolo L, Ficarra V, Zisman A, et al.: Prognostic value of histologic subtypes in renal cell carcinoma: a multicenter experience. J Clin Oncol. 2005; 23: 2763-71.

13. Scoll BJ, Wong YN, Egleston BL, Kunkle DA, Saad IR, Uzzo RG: Age, tumor size and relative survival of patients with localized renal cell carcinoma: a surveillance, epidemiology and end results analysis. J Urol. 2009; 181: 506-11.

14. Jemal A, Siegel R, Ward E, Hao Y, Xu J, Murray T, et al.: Cancer statistics, 2008. CA Cancer J Clin. 2008; 58: 71-96.

15. Aron M, Nguyen MM, Stein RJ, Gill IS: Impact of gender in renal cell carcinoma: an analysis of the SEER database. Eur Urol. 2008; 54: 133-40.

16. Bergström A, Hsieh CC, Lindblad P, Lu CM, Cook NR, Wolk A: Obesity and renal cell cancer--a quantitative review. Br J Cancer. 2001; 85: 984-90.

17. Hunt JD, van der Hel OL, McMillan GP, Boffetta P, Brennan P: Renal cell carcinoma in relation to cigarette smoking: meta-analysis of 24 studies. Int J Cancer. 2005; 114: 101-8.

18. van Dijk BA, Schouten LJ, Kiemeney LA, Goldbohm RA, van den Brandt PA: Relation of height, body mass, energy intake, and physical activity to risk of renal cell carcinoma: results from the Netherlands Cohort Study. Am J Epidemiol. 2004; 160: 1159-67.

19. Amin MB, Amin MB, Tamboli P, Javidan J, Stricker H, de-Peralta Venturina M, et al.: Prognostic impact of histologic subtyping of adult renal epithelial neoplasms: an experience of 405 cases. Am J Surg Pathol. 2002; 26: 281-91.

20. Nardi AC, Moreira Filho DC, Nardozza, A; Rios, LAS, Zequi, SC. Perfil do Câncer de Próstata no Estado de São Paulo- Detectado pela Sociedade Brasileira de Urologia-Secção São Paulo. 1st. ed. São Paulo: Lado a Lado Comunicação ed, 2005. v. 1. pp. 117.

\section{Correspondence address:}

Dr. Stênio de Cássio Zequi

Sociedade Brasileira de Urologia

Rua Bambina, 153

Rio de Janeiro, RJ, 22251-050, Brazil

Fax: + 5521 2246-4194

E-mail: steniozequi@uol.com.br 


\section{EDITORIAL COMMENT}

Our approach to kidney cancer has changed considerably in recent years. More and more tumors are now diagnosed at earlier stages. For example, smaller masses are often benign justifying the use of needle biopsy to confirm the diagnosis. This procedure was unthinkable in previous eras when most tumors were considered malignant until proved otherwise after the analysis of abdominal ultrasound or CT scans. Similarly, this increased the indications for partial nephrectomy, as well as less aggressive methods, such as cryoablation. The authors presented an epidemiologic study on renal cell carcinoma in Brazil. It is very important that we can consult these data to plan a strategy to treat our patients. Three-quarters of patients had localized disease (i.e., TNM stage I and II) and the most common histological type was clear cell carcinoma; virtually all patients underwent nephrectomy (radical or partial) for management of their RCC. The predominance of early-stage disease is corroborated by the fact that abdominal ultrasound (73.4\%) or abdominal CT scans (19.1\%) were main diagnostic methods in contrast to physical examination $(3.0 \%)$ and intravenous urography $(0.6 \%)$. Unfortunately, $85 \%$ of the patients in the study were from the southeast region of the country. Another obvious limitation of the study design is also the lack of a central pathologic review. A possible reason for the higher frequency of metastatic disease in private sector could be a referral bias, leading patients with more advanced disease to look for other specialists in private health care sector.

Dr. Antonio A. Ornellas National Cancer Institute Rio de Janeiro, RJ E-mail:ornellasa@hotmail.com

\section{REPLY BY THE AUTHORS}

Although the vast majority of the cases were from the southwest region, it reflects the participation rates of our urological community. The opportunities for study participation were rigorously the same for all members of the Brazilian Society of Urology (SBU). We must remember that more than half of SBU members are in the Brazil southeast states. Based on this inedited data, the SBU must develop new approaches to attract more Brazilian urologists for National trials and surveys.

Although the lack of central pathologic review be a limitation of the study design, as already discussed in the paper, it may represents a new opportunity to SBU to promote an approach with other National medical societies, specially the Brazilian Society of Pathology. 